\title{
Todas as criaturas do mundo: a arte dos mapas como elemento de orientação geográfica!
}

Dante Martins Teixeira ${ }^{2}$

RESUMO: Vagos em seu traçado e pródigos em figuras de seres reais ou fabulosos, a iconografia dos mapas medievais cumpria papel nada desprezível para o reconhecimento de terras virtualmente desconhecidas pela Cristandade. Em um mundo sem latitude e longitude confiáveis, os acidentes da paisagem, os povos existentes e até mesmo determinados componentes da fauna e flora poderiam transformar-se em variáveis de extrema importância para a orientação geográfica. Apesar de alcançarem maior precisão nas tentativas de representar o espaço geográfico, experimentarem considerável avanço na determinação da latitude e prosseguirem na busca de um método prático para obter a longitude, os cartógrafos da época dos Grandes Descobrimentos ainda se preocuparam em figurar elementos notáveis - imaginários ou não - capazes de auxiliar na orientação dos viajantes nas mais diferentes regiões do globo. Com a crescente expansão europeia e a autêntica revolução científica em curso no século XVII, os extensos comentários e as vistosas representações da natureza e dos habitantes dos locais perderiam rapidamente o papel de referência nos mapas seiscentistas, conservando apenas seu valor estético e econômico. A chegada do século XVIII consolidaria a definitiva transformação das ilustrações em um elemento essencialmente decorativo, sem qualquer outro papel relevante em termos cartográficos. Além de menos numerosas, as figuras amiúde tendem a uma certa estilização e acentuam seu deslocamento para a periferia dos mapas, que soem apresentar alguma ornamentação apenas nas cártulas ou cartuchos. Apesar de muitas vezes conservarem algum tipo de relação com o espaço geográfico considerado, os motivos escolhidos também podem adquirir relativa independência, havendo numerosos casos de alegorias e composições com variadas figuras mitológicas, bem como representações de caráter histórico destinadas a ressaltar o poderio de um determinado ator políitico.

PALAVRAS-CHAVE: Cartografia histórica. Cartografia holandesa. Cartografia quinhentista. Cartografia seiscentista. Iconografia. Iconologia.

ABSTRACT: Vague in the outlines and abounding in figures of real or fabulous creatures, the iconography of medieval maps played a significant role in helping users to recognize lands
1. Durante os estudos prévios e execução desse trabalho, contamos com a indispensável colaboração de Iris Kantor (Departamento de História, Faculdade de Filosofia, Letras e Ciências Humanas, Universidade de São Paulo), Beatriz Piccolotto Siqueira Bueno (Departamento de História, Faculdade de Arquitetura e Urbanismo, Universidade de São Paulo) e Nelson Papavero (Museu de Zoologia, Universidade de São Paulo), que apresentaram comentários e sugestões de grande valia para o desenvolvimento do texto final. Por fim, cabe ressaltar o apoio concedido pelo Conselho Nacional de Desenvolvimento Científico e Tecnológico (CNPq) às pesquisas realizadas pelo autor durante os últimos anos.

2. Professor Adjunto do Departamento de Vertebrados, Museu Nacional-UFRJ, Rio de Janeiro (RJ). Pós-Doutorando do Instituto de Estudos Brasileiros, Universidade de São Paulo (SP). Bolsista do Conselho Nacional de Desenvolvimento Científico e Tecnológico (CNPq). E-mail: $<$ dante.teixeira@pq.cnpq.br>. 
3. W. B. Greenlee (1938) e D. M. Teixeira \& N. Papavero (2006).

4. Essas araras-vermelhas seriam mencionadas por Domenico Pisani di Giovanni, embaixador de Veneza na Espanha e Portugal, e por seu erudito secretário Giovanni Matteo Camerini, chamado "Il Cretico". Delas também falaria Bartolomeo Marchionni, rico banqueiro florentino residente em Lisboa e um dos quatro armadores da "Anunciada", pequena caravela redonda que se revelou a mais rápida de todas as embarcações da esquadra de Cabral. Para maiores detalhes, vide J. Cortesão (1922), W. B. Greenlee (1938), M. J. Guedes (1997), T. O. M. de Souza (1946) e D. M. Teixeira \& \& N. Papavero (2006).

5. Bem exemplificados por F. da Montalboddo (1507) e G.B. Ramusio (1550).

6. A expressão "Terra de li Papaga" ("Terra dos Papagaios") surge pela primeira vez na carta de Giovanni Matteo Camerini, "Il Cretico", escrita ao doge Agostino Barbarigo em 27 de junho de 1501, adquirindo maior notoriedade graças à versão do original publicada no famoso "Paesi Novamente Retrovati", um dos "livros de viagem" mais celebrados do século XVI. Vide F. da Montalboddo (1507)

7. Embora as aves trazidas para Lisboa provavelmente fossem araras-vermelhas (Ara chloroptera), o "Planisfério de Cantino" na verdade retrata três araracangas (Ara macao), uma segunda variedade de grande porte e plumagem escarlate frequentemente confundida com a anterior. Tal equívoco estaria destinado a sustentar-se por mais de 300 anos, sendo desfeito apenas com a descrição de Ara chloroptera como espécie independente em meados do século XIX. Vide G. R. Gray (1859) e D. M. Teixeira \& N. Papavero (2006) that were virtually unknown to Christendom. In a world with no reliable latitudes and longitudes, the land contours, inhabitants and even certain elements of fauna and flora could become variables of utmost importance for geographic orientation. Notwithstanding the higher levels of precision achieved in their efforts to represent geographic space, the considerable advancements made in latitude determination, and their continuous pursuit of a practical method for the establishment of longitudes, the cartographers of the Age of Discoveries still went to the trouble of depicting notable elements - whether real or imaginary - to help travelers get their bearings around different regions of the globe. As the presence of Europeans continued to expand and an authentic scientific revolution took place in the $17^{\text {th }}$ century, the lengthy notes and eye-catching representations of nature and local inhabitants soon lost their utility as points of reference on $17^{\text {th }}$-century maps to become mere accessories of aesthetic and commercial value. The advent of the $18^{\text {th }}$ century consolidated, once and for all, the transformation of such illustrations into essentially decorative elements with no other relevant role to play in mapmaking. In addition to decreasing in number, the figures became more stylized and moved to the borders of the maps as ornamental motifs. Although they often maintained some sort of relation with the geographic space depicted on the map, the motifs chosen could also constitute a rather independent element. In fact, allegories, compositions with a variety of mythological figures, and historical representations were often used to underscore the power of certain political agents.

KEYWORDS: Historical cartography. Dutch cartography. $16^{\text {th }}$-century cartography. Iconography. lconology.

Entre as novidades do além-mar trazidas por Pedro Álvares Cabral no retorno de sua aziaga viagem à Índia (1500-1501), nenhuma atrairia tanto a atenção dos europeus quanto duas araras-vermelhas adquiridas em uma nova terra encontrada 44 dias após a partida da expedição de Lisboa ${ }^{3}$. Descritas pelo cronista Pero Vaz de Caminha como "papagaios vermelhos muito grandes e formosos", essas aves seriam consideradas dignas de particular admiração por todos os observadores da época, inclusive os diferentes missivistas italianos prontos a dar notícia sobre as navegações ibéricas aos seus conterrâneos ${ }^{4}$. Ao virem à luz nos mais prestigiosos "livros de viagens" do século XVI5, alguns desses testemunhos alcançariam considerável repercussão, terminando por conferir o significativo nome de "Terra dos Papagaios" aos novos domínios portugueses no Ocidente ${ }^{6}$.

Ultrapassando a esfera dos textos quinhentistas, essa marcada relação logo se refletiria nos mapas, onde os espaços do vasto território recém descoberto por Portugal continuariam a ser preenchidos com desenhos de psitácidas mesmo depois da designação de "Terra dos Papagaios" há muito ter sido substituída por "Brasil" na linguagem corrente. Embora oscilassem entre as figuras demasiado estilizadas do chamado "Atlas Miller" atribuído a Lopo Homem (1519) e as minuciosas pinturas observadas no famoso "Planisfério de Cantino" (1502)\%, por longo tempo os papagaios e afins seriam uma presença constante nos mapas dedicados ao Brasil, havendo mesmo casos de cartógrafos que, por não terem maiores detalhes acerca das aves do Novo Mundo, representariam em seu lugar periquitos asiáticos conhecidos na Europa desde a Antiguidade. Tal equívoco 
encontra-se bem marcado, por exemplo, pelos espécimens do gênero Psittacula encontrados na "Carta da América e Filipinas" de Alonso de Chaves (1533).

Da mescla de papagaios, macacos e "indios canibais" com cenas da extração do "paus-de-tinta" nasceria o retrato dominante do Brasil na iconografia cartográfica do século XVI, imagem que associa a fauna, a flora e os habitantes do nosso litoral mencionados pelos antigos cronistas $^{9}$ com os registros da única atividade econômica de vulto levada a cabo por colonizadores e aventureiros ${ }^{10}$. Semelhante união seria perpetuada mesmo nos primeiros mapas impressos, segundo atesta a xilogravura preparada por Giacomo Gastaldi para o terceiro volume da famosa "Delle Navigationi e Viaggi" de Giovanni Battista Ramusio"1 (Figura 1).

Longe de constituir fato isolado, as ilustrações encontradas nos primeiros mapas dedicados ao Brasil parecem refletir uma antiga herança europeia, pois a
8. Os psitácidas do Novo Mundo chegariam à Europa poucos anos após a viagem de Colombo, conforme demonstra a imagem de uma arara-vermelha - talvez uma araracanga (Ara macao) presente no "Retrato do Casal Cuspinian", díptico de Lucas Cranach pintado em Viena entre 1502 e 1503. Por serem bem mais vulgares, entretanto, animais africanos e asiáticos terminariam por substituir os da América em numerosos mapas, trocas que envolviam "macacos", "papagaios", "felinos" e outras categorias zoológicas arbitrárias representadas em

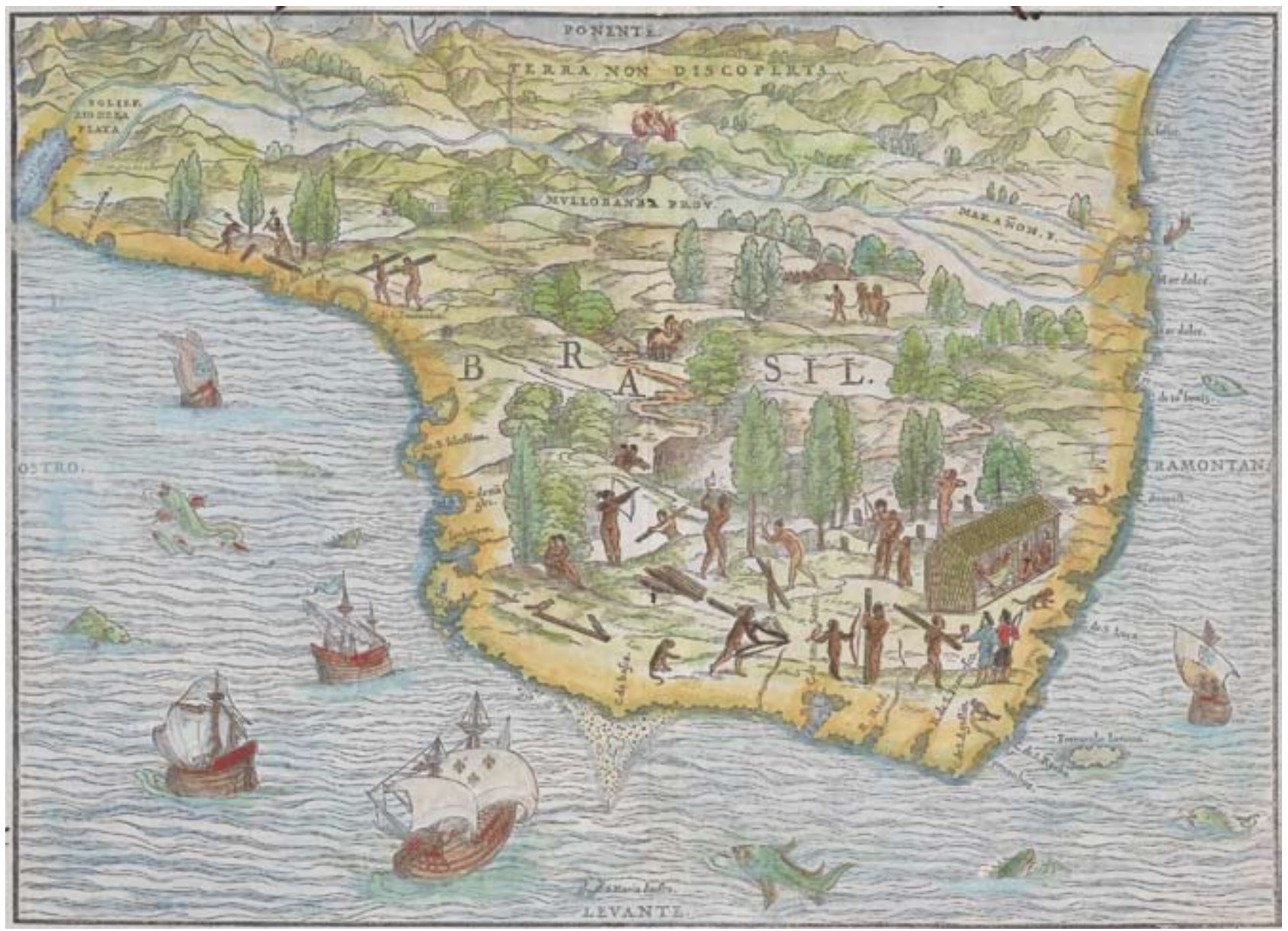

Figura 1 - O Brasil, segundo xilogravura preparada por Giacomo Gastaldi para o terceiro volume da famosa "Delle Navigationi e Viaggi" de Giovanni Battista Ramusio (1556). Instituto de Estudos Brasileiros / USP (acervo depositado temporariamente pela Justiça Federall, São Paulo. 
ambos lados do oceano. Ao invés de uma espécie do Novo Mundo, a "Carta da América e Filipinas" de Alonso de Chaves retrata um periquito do gênero Psittacula (provavelmente Psittacula krame$r i$ ), aves com ampla distribuição na África e Ásia que já eram conhecidas desde a Antiguidade por gregos e romanos. Vide W. George (1969), H. Sick (1984), J. Pollard (1977), J.M.C. Toynbee (1973) e S. Zuckerman (1998).

9. Por exemplo J. de Lery (1578), H. Staden (1557) e A. Thevet (1557)

10. F. Lestringant (1987), B. J. de Souza (1939) e Z. Ziebell (2002).

11. G. B. Ramusio (1556).

12. W. George (1969).

13. J. Favier (1991) e J. P. Roux (1985).

14. L. A. Brown (1949) e L. Martín-Merás (1993).

15. C. J. Solinus (1587).

16. L. A. Brown (1949), O Dreyer-Eimbcke (1988), W George (1969), C. Jacob (1992) e C. Moreland \& D. Bannister (1989).

17. K. Kretschmer (1942). cartografia medieval muitas vezes incorporava figuras dos habitantes e até mesmo dos animais - imaginários ou não - das diferentes regiões consideradas ${ }^{12}$. Até meados do século XV, entretanto, boa parte do escasso conhecimento sobre o resto do mundo disponível no Ocidente cristão vinha dos clássicos, era de origem árabe ou procedia dos poucos viajantes que lograram estender suas peregrinações a um Oriente longínquo e quase fabuloso, aproveitando-se da hegemonia e estabilidade do império mongol ${ }^{13}$. Curiosamente, os estudiosos do período relegariam a obra de Claudius Ptolomaeus, maior geógrafo da Antiguidade, ao completo esquecimento por centenas de anos a fio, enquanto valorizavam outras fontes amiúde marcadas pelo forte caráter eclesiástico e religioso dominante na época.

Entre todos os autores, nenhum teria exercido papel tão decisivo quanto Caius Julius Solinus, gramático latino do século II d.C. responsável por uma sucinta compilação da "Historia Naturalis" de Plínio, "o Velho", acrescida de várias observações próprias ${ }^{14}$. Mostrando-se assaz conveniente para o esforço desenvolvido pelos primeiros "Pais da lgreja" em preservar a cultura clássica através de versões resumidas postas a serviço do dogma cristão, a "Collectanea Rerum Memorabilium" de Solinus obteria ampla difusão já no século VI, convertendo-se em uma das obras mais afamadas da ldade Média e exercendo grande influência no pensamento europeu pelo menos até o Renascimento, quando ainda era objeto de várias edições ${ }^{15}$.

Na prática, o trabalho dos cartógrafos medievais estendia-se além das acanhadas fronteiras das terras conhecidas, penetrando no horror de um mundo ignoto povoado de monstros e maravilhas, um imenso espaço vazio coabitado pelos piores pesadelos e as mais sedutoras fantasias, universo destinado a permanecer sempre além das estreitas barreiras do real. Não deve causar surpresa, portanto, o fato de os mapas então produzidos mostrarem-se vagos em seu traçado e pródigos em figuras de seres reais ou fabulosos, colocando rinocerontes, leões dromedários, elefantes e selvagens de pele escura lado a lado com grifos, dragões, unicórnios, trogloditas, ciclopes e toda sorte de seres fantásticos mencionados para os países distantes. No entanto, a delicada tarefa de traçar o contorno de territórios nunca vistos com base em notícias imprecisas ou pouquíssimo detallhadas apresentava inúmeros problemas, pois os recursos disponíveis sequer permitiam uma representação exata de litorais há muito devassados.

Malgrado existam numerosas análises relativas ao assunto ${ }^{16}$, vale lembrar que essa iconografia também cumpria papel nada desprezível para o reconhecimento de terras virtualmente desconhecidas pela Cristandade. Com efeito, em um mundo sem latitude e longitude confiáveis, os acidentes da paisagem, os povos existentes e até mesmo determinados componentes da fauna e flora poderiam transformar-se em variáveis de extrema importância para a orientação geográfica. Na verdade, os mapas medievais estão repletos tanto de vistosas ilustrações quanto de extensos comentários escritos sobre a natureza e os habitantes dos locais retratados, conjunto de referências significativo o suficiente para ocupar parcela razoável do espaço disponível ${ }^{17}$.

Conforme demonstra o caso do "Planisfério de Cantino" e do "Atlas 
Miller", essa mesma tendência seria preservada na época dos Grandes Descobrimentos, quando as sucessivas levas de exploradores do século XV - e todos seus incontáveis sucessores - partiriam para transformar esse "universo maravilhoso" em realidade, inundando a Europa com notícias de novas terras, animais estranhos, outras gentes, da fábula tornada verdade ${ }^{18}$. Apesar de alcançarem maior precisão nas tentativas de representar o espaço geográfico, experimentarem considerável avanço na determinação da latitude e prosseguirem na busca de um método prático para obter a longitude, os cartógrafos do período ainda se preocupavam em figurar elementos notáveis - imaginários ou não capazes de auxiliar na orientação dos viajantes nas mais diferentes regiões do globo, fenômeno que envolvia até mesmo os animais ${ }^{19}$.

No entanto, a entusiástica incorporação das novidades do além-mar promovida pela cartografia quinhentista também refletia ditames econômicos, estéticos e a irresistível atração dos europeus pelo exótico e pelo desconhecido. Apesar de permeados pelas mais extraordinárias fantasias, esses relatos terminariam por difundir a surpreendente visão de um mundo real muito mais vasto, complexo e diversificado do que poderia supor a mais desvairada imaginação, fato destinado a gerar profundas inquietudes e uma insaciável curiosidade pelas terras distantes. Presente nos mais diferentes aspectos do cotidiano, tal influência ganharia corpo de forma bastante nítida nos chamados "livros de viagem", modalidade de grande apelo literário que costumava permanecer avessa aos interesses acadêmicos, voltando-se para a divulgação das maravilhas do Novo Mundo ou do Oriente em uma esfera bem mais popular, pouco afeita ao latim dos eruditos e às preocupantes e intricadas questões filosóficas suscitadas pelas surpreendentes descobertas levadas a cabo no outro lado do oceano ${ }^{20}$.

Entre vários títulos dignos de nota, as célebres "Viagens de Sir John Mandeville" constituem um exemplo cabal desse tipo de literatura tão apreciada na ldade Média. Tendo começado a circular entre 1356 e 1366, seu texto estaria disponível em todos os principais idiomas europeus por volta de 1400, havendo notícias sobre um número bastante considerável de versões manuscritas no começo do século XVI ${ }^{21}$. Objeto de sucessivas edições até os nossos dias, as "Viagens de Mandeville" parecem ter sido baseadas em mais de uma dúzia de fontes distintas, constituindo um complexo quebra-cabeça entremeado tanto de fantasias que já eram velhas no seio da Cristandade do medievo quanto de lendas destinadas a perdurar pelo menos até o século XVIII.

A expansão europeia observada a partir do século XV e a autêntica revolução científica em curso desde o século XVI conduziriam os cartógrafos seiscentistas a produzir mapas cada vez mais acurados, atividade que assume uma nova feição graças às descobertas de Galileo Galilei sobre os movimentos das luas de Júpiter, cujo comportamento peculiar podia servir como um autêntico "relógio sideral" muito útil para a determinação da longitude ${ }^{22}$. Nesse quadro de acentuadas mudanças favoráveis a uma melhor orientação em termos geográficos, os extensos comentários e as vistosas representações da natureza e dos habitantes dos locais perderiam rapidamente o papel de referência, conservando apenas
18. Ao fascínio dos "prodígios" viria somar-se uma perplexidade crescente face às notícias sobre um elenco cada vez maior de animais sem paralelo com a fauna conhecida até então, descoberta que levaria muitos europeus a conferir nova importância a certos clássicos tidos como fantasiosos. Entre as curiosidades trazidas por Cabral, Bartolomeo Marchionni (vide nota 4) menciona haver "muitas espécies de aves e animais por nós desconhecidos e jamais vistos, à maneira daquelas coisas que Plínio contava nas suas histórias, [as quais] eram consideradas mentirosas e - pelo que hoje se vê pode-se dizer que tinham algo de verdade" ("Anno rechato molte ragoni d'ucelli $\mathrm{e}$ animali a noi inchongniti e no mai piu visti in modo chelle chose rachontava Plinio nelle suo storie. Erano tenute bugie e per quello oggi di si vede si puo dire n'avasse qualche notizia" no original). Vide D. M. Teixeira \& N. Papavero (2006).

19. Até meados do século XVII, por exemplo, as aves marinhas de Fernando de Noronha eram numerosas a ponto de servirem de orientação aos pilotos em rota para o arquipélago. De fato, ao descrever os cuidados necessários para uma aproximação segura, Pero Lopes de Sousa estabelece que todo o navegador deveria atentar para as aves marinhas, pois "a barlavento vereis muitas aves as mais rabiforcados $\mathrm{e}$ alcatrazes pretos; e a julavento vereis muito poucas aves, e as que virdes serão alcatrazes brancos". Vide P. L. de Sousa (1940) e D. M. Teixeira \& J. B. Nacinovic (2002).

20. A descoberta de uma crescente multidão de seres vivos sem nada em comum com a fauna e flora conhecida pelos europeus não só tornava premente a necessidade de um sistema de referência universal que a todos nomeasse, como reforçava indiscretas conjeturas acerca 
da pluralidade da criação e dúvidas heréticas sobre a cronologia exposta no Livro Sagrado, criando sérias indagações quanto à verossimilhança e pertinência de várias passagens bíblicas. Na verdade, seria de fato possível construir uma arca grande o suficiente para abrigar semelhante quantidade de animais? Caso positivo, se estes haviam sido salvos juntos de um "dilúvio universal", porque tantos ocorriam apenas em determinadas partes da terra e não em outras? Toda essa enorme diversidade poderia ser mesmo originária de um único local? Durante os séculos XVI e XVII, algu- seu valor estético e econômico ${ }^{23}$. Se examinarmos o afamado mapa da "America" de Jodocus Hondius (Figura 2), um dos maiores cartógrafos holandeses ativos no século XVII, salta aos olhos que as figuras e anotações migram do interior do espaço continental para a periferia, cedendo lugar a um número crescente de rios, montanhas, cidades e demais componentes da paisagem física e humana. No entanto, as imagens ainda constituíam um recurso importante o suficiente para inspirar cuidados nada desprezíveis, pois Hondius mostra-se bastante fiel à tradição ao ornamentar seus trabalhos com elementos típicos das diferentes regiões retratadas, seguindo fontes das mais diversas ${ }^{24}$.

Ao lado das proverbiais araras e tucanos, a "America" de Hondius apresenta ilustrações bem mais elaboradas, por exemplo uma cena de costumes alusiva ao preparo do cauim por índios brasileiros calcada na versão das gravuras originais de André Thevet vinda à luz no terceiro volume das "Grandes Viagens" de Theodore de Bry (Figura 3)25. Próxima ao sul do continente, uma segunda figura menos

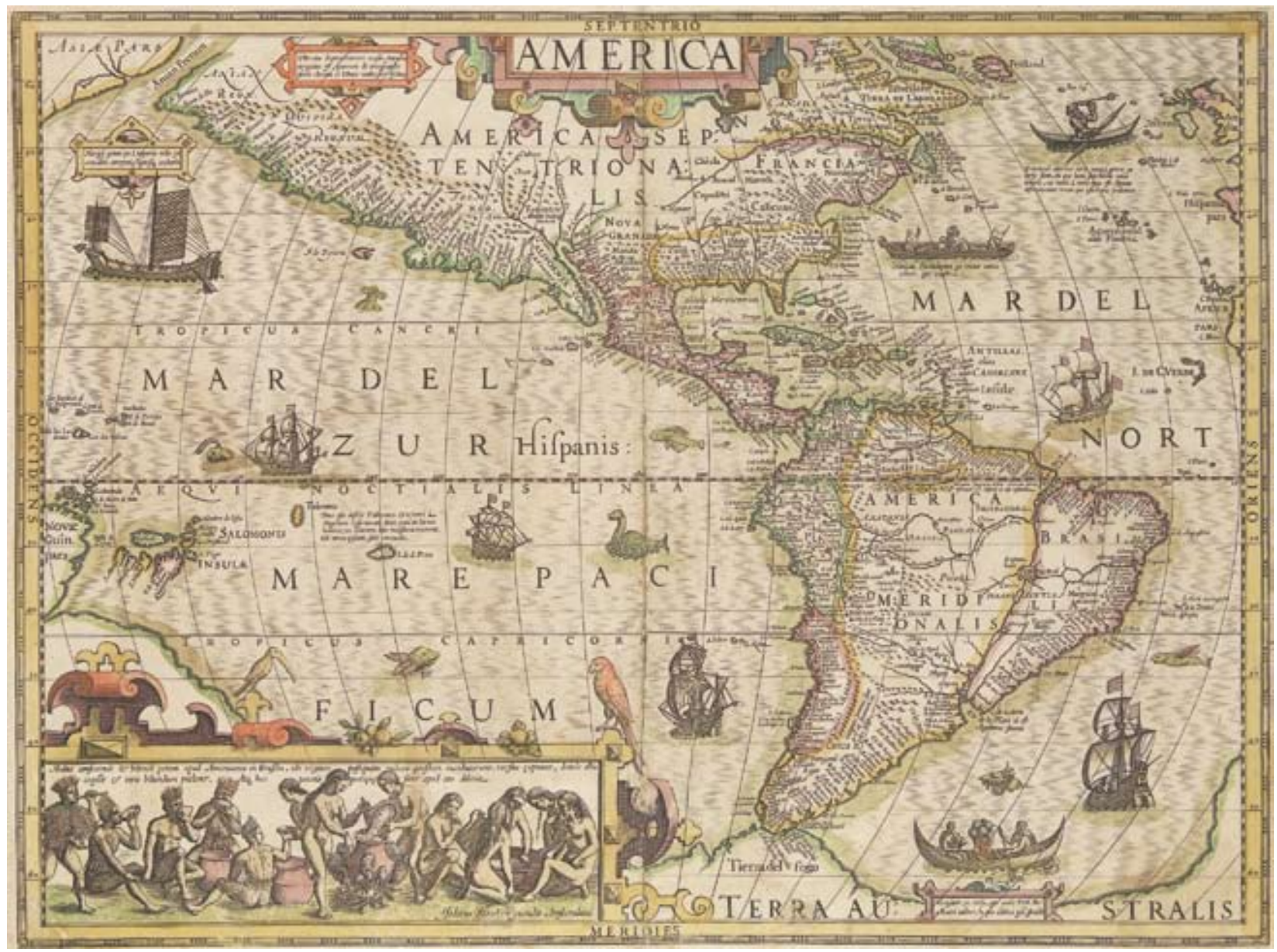

Figura 2 - A "America" de Jodocus Hondius (ca. 1606). Instituto de Estudos Brasileiros / USP (acervo depositado temporariamente pela Justiça Federall, São Paulo. 


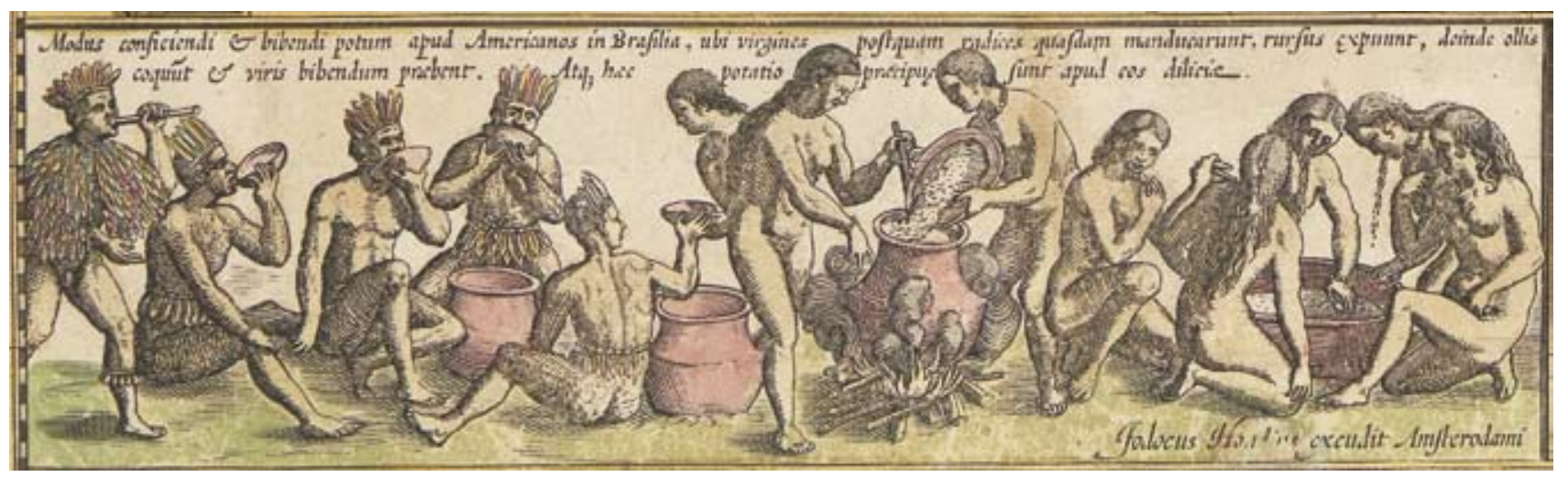

Figura 3 - Índios preparando e consumindo o cauim. Detalhe da "America" de Jodocus Hondius (ca. 1606). Instituto de Estudos Brasileiros / USP (acervo depositado temporariamente pela Justiça Federall, São Paulo.

conspícua mostra uma família de indígenas seminus aquecendo-se nas chamas de uma fogueira acesa no bojo de uma frágil embarcação (Figura 4). Encontrado em outros mapas do mesmo autor, esse curioso detalhe diz respeito aos primeiros contatos com os Alakaluf, nação de índios canoeiros do Estreito de Magalhães e arredores mencionada por cerca de 16 relatos dos séculos XVI e XVII26.

Guardadas as devidas proporções, algo semelhante pode ser observado no chamado "Mapa de Marcgrave", talvez a mais notável expressão da cartografia impressa referente ao Brasil vinda à luz no século XVII. Tendo como autor Georg Marcgrave, astrônomo alemão que aqui permaneceu durante o governo de mas das tentativas mais brilhantes de responder a tais perguntas seriam articuladas pelos jesuítas Joseph de Acosta e Athanasius Kircher. Para maiores detalhes, vide J. de Acosta (1590), J. Browne (1983), M. B. Campbell (1988), A. Gerbi (1978, 1993), C. J. Glacken (1976), C. C. Kappler (1999), A. Kircher (1675), M. Mollat (1984) e N. Papavero et al (1997).

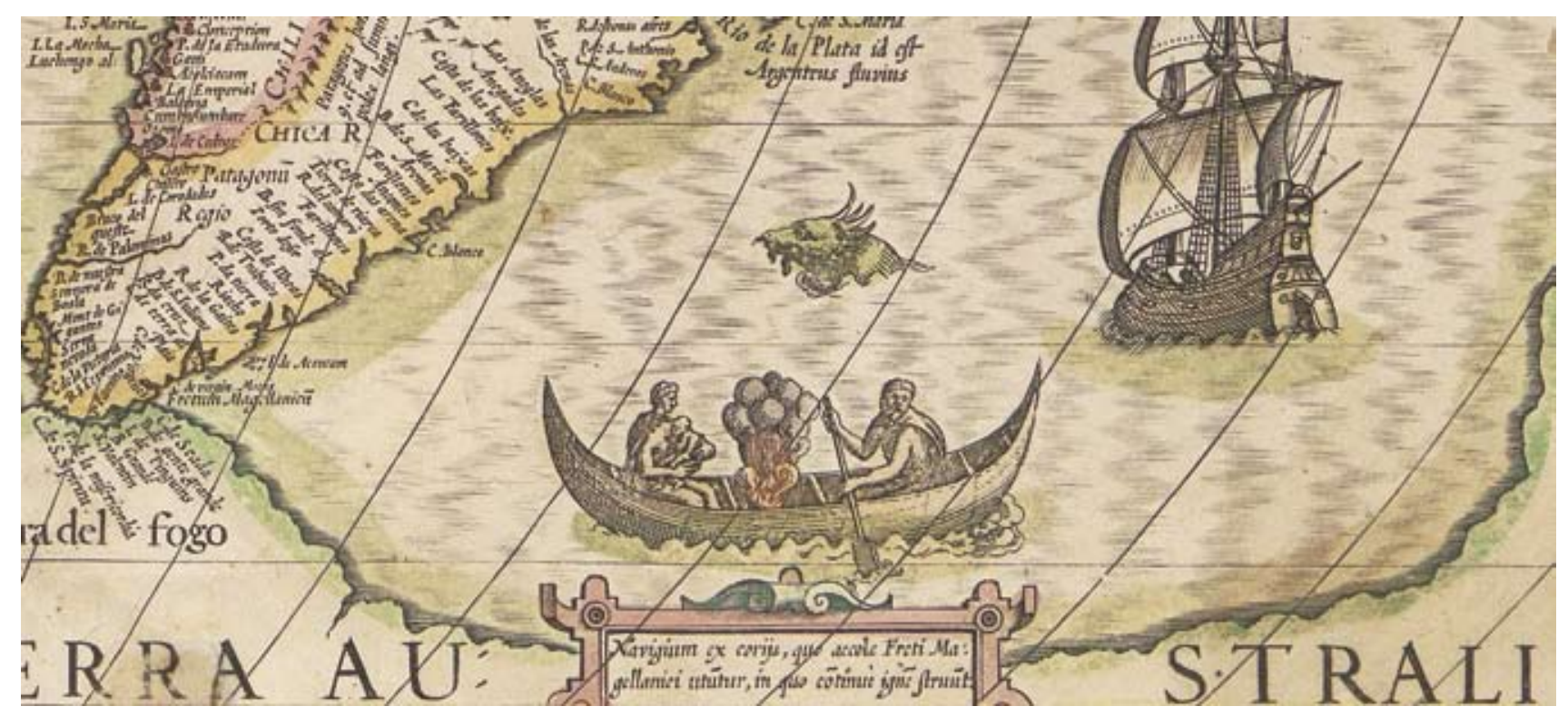

Figura 4 - Canoa alakaluf. Detalhe da "America" de Jodocus Hondius (ca. 1606). Instituto de Estudos Brasileiros / USP (acervo depositado temporariamente pela Justiça Federall,, São Paulo.

Annals of Museu Paulista. v. 17. n.1. Jan. - June 2009. 
21. C. W. Mosley in J. Mandeville (1983)

22. L. A. Brown (1949) e D. Sobel (1995).

23. K. Zandvliet (2002).

24. R. V. Tooley (1952).

25. T. de Bry (1592) e A. Thevet (1557)

26. Apesar de os misteriosos fogos avistados em 1520 por Fernão de Magalhães terem sido usualmente atribuídos aos indígenas do Estreito, o
Maurício de Nassau (1 637-1644), essa carta retrata a faixa costeira nordestina compreendida entre Sergipe e Rio Grande do Norte. Seu desenho original teria sido concluído por volta de 1643, mas a primeira versão só seria publicada pelo editor holandês Joan Blaeu em 1647, havendo uma segunda tiragem de Huych Allard datada de 1659 e uma terceira preparada por Clemendt de Jonghe em 166427. Assumindo a forma de um grande mural com cerca de $115 \mathrm{~cm}$ por 155 cm, o "Mapa de Marcgrave" costuma ser visto como o apogeu da cartografia produzida durante o período do Brasil Holandês (1624-1654), sendo reputado como a mais perfeita representação geográfica do nosso país existente até o início do século XIX (Figuras 5 a 7 ).

Tal como ocorre na "America" de Hondius, as ilustrações do "Mapa de Marcgrave" obedeceriam uma razão eminentemente decorativa, apesar de

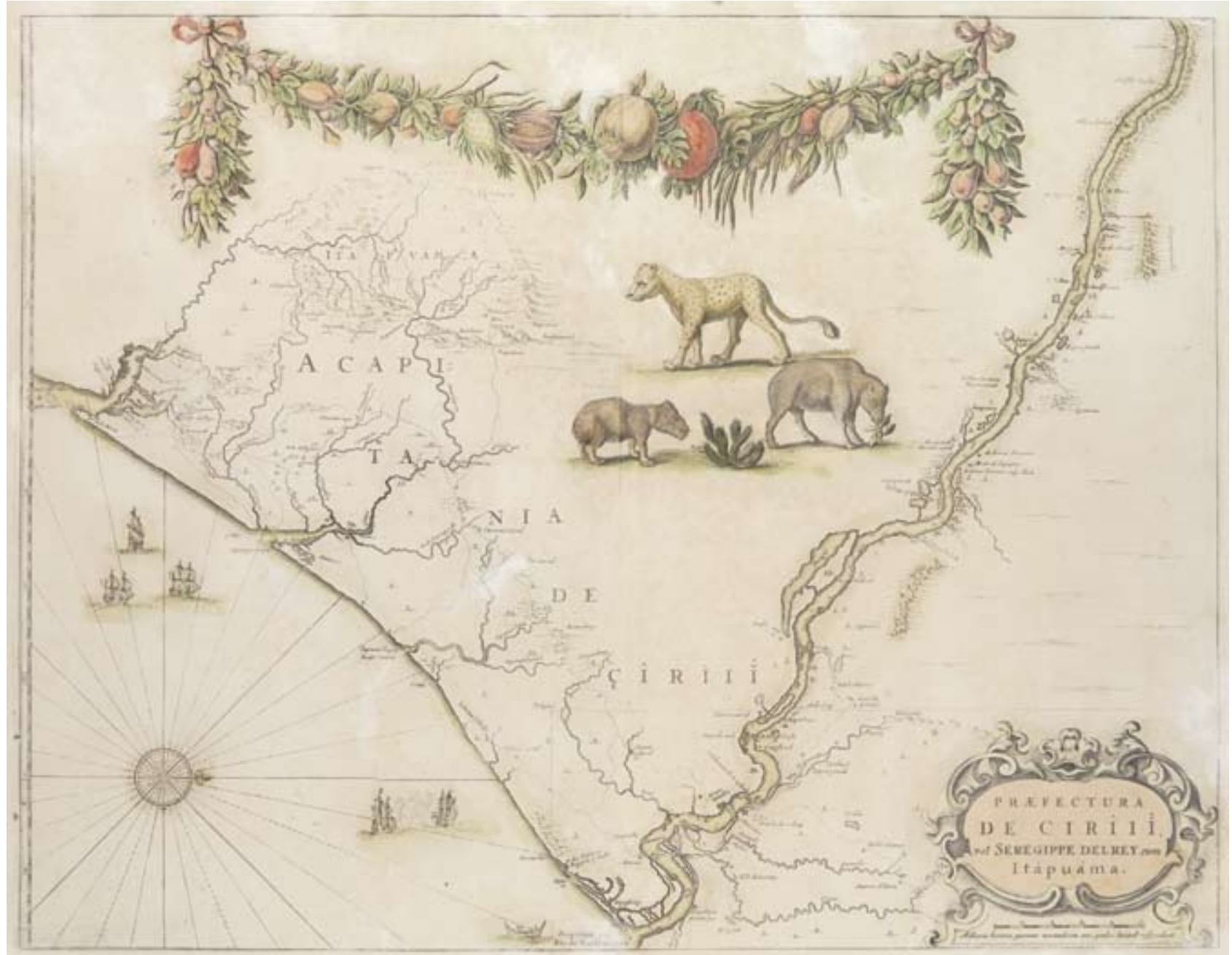

Figura 5 - Parte do "Mapa de Marcgrave" publicada no "Rerum per Octennium in Brasilia" de Gaspar Barlaeus (1647). Instituto de Estudos Brasileiros / USP (acervo depositado temporariamente pela Justiça Federall), São Paulo. 


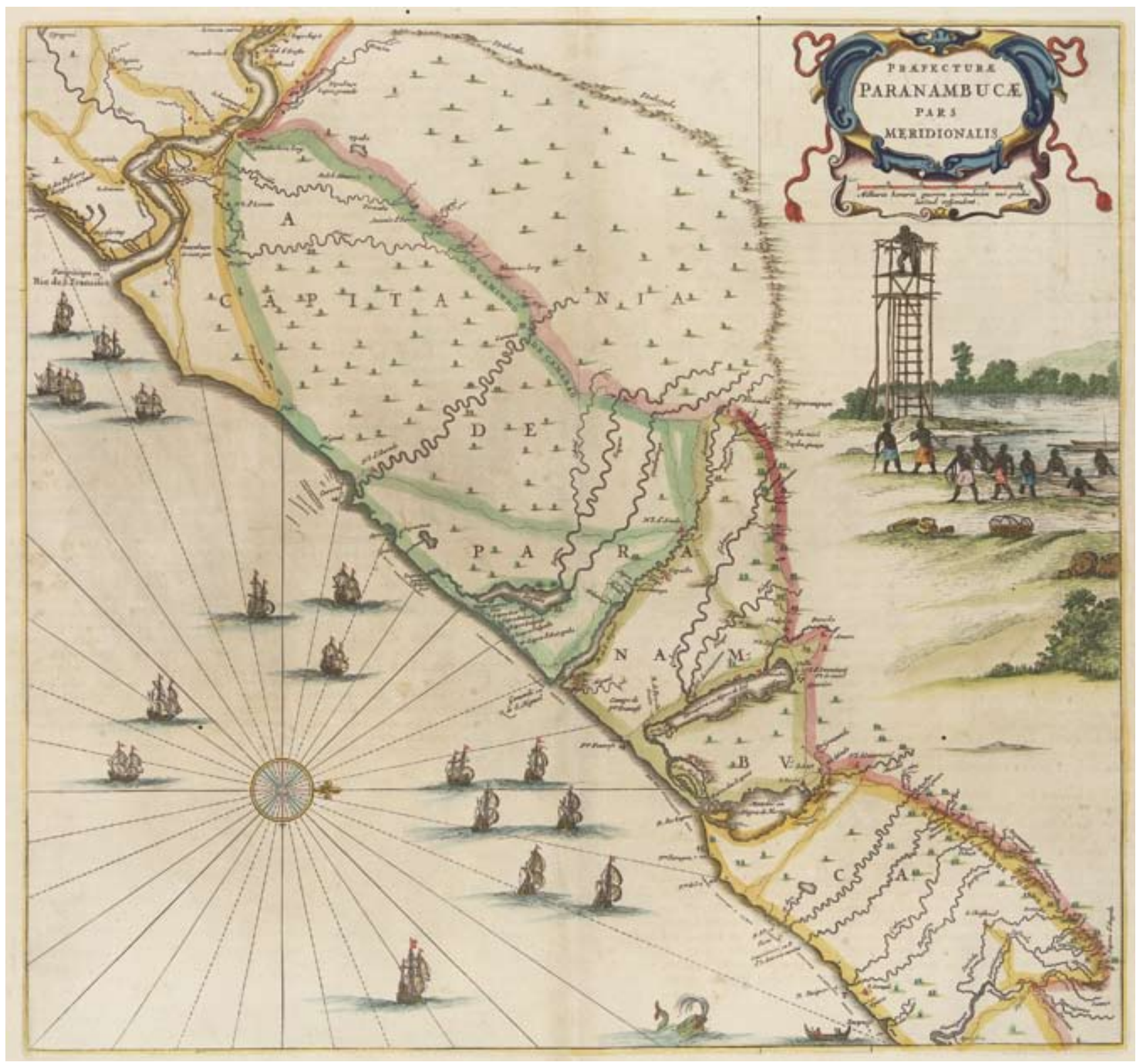

Figura 6 - Parte do "Mapa de Marcgrave" publicada no "Rerum per Octennium in Brasilia" de Gaspar Barlaeus (1647). Instituto de Estudos Brasileiros / USP (acervo depositado temporariamente pela Justiça Federal). 


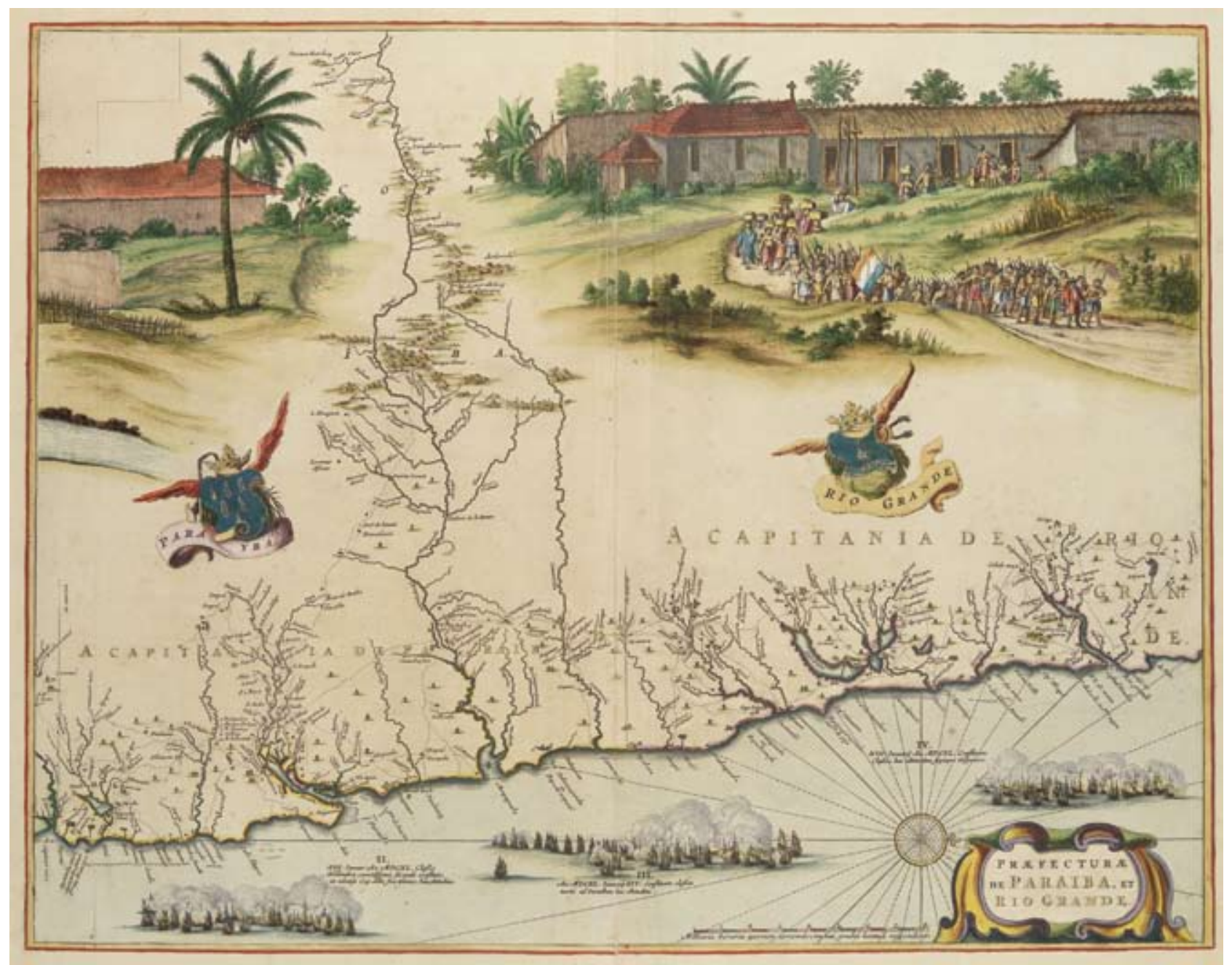

Figura 7 - Parte do "Mapa de Marcgrave" publicada no "Rerum per Octennium in Brasilia" de Gaspar Barlaeus (1647). Instituto de Estudos Brasileiros / USP (acervo depositado temporariamente pela Justiça Federal), São Paulo.

primeiro contato efetivo com os Alakaluf ocorreria apenas seis anos mais tarde, durante a expedição do Frei Garcia Jofre de Loayasa (in G. F. Oviedo y Valdez, 1557). Quanto à origem da figura presente no mapa de Jodocus Hondius, vale lembrar que algumas publicações holandesas do começo do século XVII tentariam retratar a fisionomia e certos aspectos da cultura material desses indígenas. Na verdade, as gravuras referentes aos Alakaluf envolverem elementos próprios das terras conquistadas pela Companhia das Indias Ocidentais. Atribuídas ao pintor holandês Frans Post, essas gravuras retratam numerosos artefatos indígenas e animais exóticos como a onça (Panthera onca), a ema (Rhea americana), o tamanduá-bandeira (Myrmecophaga tridactyla) e a preguiça (Bradypus variegatus), além de cenas de costumes bem mais complexas. Os motivos escolhidos abrangem desde a preparação do açúcar em um engenho e os trabalhos de moagem em uma casa de farinha até o manejo de uma rede de arrasto por pescadores e grupos de indígenas caçando ou combatendo. Tampouco faltam alusões ao poderio e feitos dos invasores, tópico lembrado tanto pelos brasões criados por Nassau para as capitanias da região (Pernambuco, Itamaracá, Paraíba e Rio Grande) quanto por imagens das quatro batalhas navais 
travadas, em janeiro de 1639, pelas esquadras do almirante Willen Corneliszoon Loos e de Dom Fernando de Mascarenhas, conde da Torre e Governador-Geral do Brasil.

Entre outros aspectos relevantes, o "Mapa de Marcgrave" surge como uma das primeiras cartas impressas sobre o Brasil a adotar um código de representação formal, ferramenta conhecida pelo menos desde o século XIV. Apresentando-se como alternativa capaz de transmitir um considerável volume informações de forma prática e expedita, esses conjuntos arbitrários de símbolos e/ou cores com significado definido tornar-se-iam cada vez mais frequentes a partir de 1400, muito contribuindo para transformar as imagens presentes nos mapas em mero elemento estético. Além de adotar fórmulas consagradas na cartografia para figurar montanhas, rios, alagadiços e outros acidentes semelhantes ${ }^{28}$, Marcgrave explicitaria o sentido de 18 símbolos, a maioria dos quais dedicada a certos elementos da paisagem humana como cidades, povoações, fortalezas, currais, aldeias indígenas etc. Não obstante, o autor também seria um dos primeiros geógrafos a lançar mão desse recurso para diferenciar dois tipos de vegetação encontrados no Brasil, distinguindo o "mato" (i.e. as formações florestais da Mata Atlântica) das "campinas", provável referência às áreas abertas compostas pelos enigmáticos "tabuleiros" nordestinos 29 .

A chegada do século XVIII consolidaria a definitiva metamorfose das ilustrações em elemento essencialmente decorativo sem maior relevância em termos cartográficos. Além de menos numerosas, as figuras amiúde tendem a uma certa estilização e acentuam seu deslocamento para a periferia dos mapas, que soem apresentar alguma ornamentação apenas nas cártulas ou cartuchos. Apesar de muitas vezes conservarem algum tipo de relação com o espaço geográfico considerado, os motivos escolhidos podem adquirir relativa independência, havendo numerosos casos de alegorias e composições com variadas figuras mitológicas, bem como representações de caráter histórico destinadas a ressaltar o poderio de um determinado ator político (Figura 8).

Datado de 1775, o "Mapa Geográfico da América Meridional" de Juan de la Cruz Cano y Olmedilla exemplifica como até mesmo os suntuosos mapas murais refletiriam essas tendências (Figura 9). Conforme esperado, as imagens ocupam as margens da carta, onde se observa uma verdadeira guirlanda de frutas e flores tropicais as mais diversas. Ao longo da borda direita, surge uma sequência de brasões indicativos sobretudo dos domínios espanhóis no Novo Mundo. O mesmo caráter laudatório é reforçado pela presença de um busto de Colombo acompanhado da sugestiva inscrição em verso ("A Castilla y á Leon, Nuevo Mundo dió Colón"). Mais abaixo, três figuras femininas personificam uma das pedras angulares do discurso colonialista vigente ao retratar a Europa como uma senhora coroada cavalgando um imponente leão que detém um cetro entre as patas dianteiras. Esta majestosa rainha tem ao seu lado a salvação trazida pela lgreja, aqui representada sob a forma de uma mulher velada carregando a cruz e o cálice da comunhão. Ambas fitam uma exótica jovem de pernas nuas que monta um monstruoso jacaré muito estilizado e traz diversos adereços de incluídas nos relatos de B. J. Potgieter (1600) e O. van Noort (1601) podem ter servido de inspiração a mais de um autor, conforme demonstram as pranchas pertencentes ao nono volume das famosas "Grandes Viagens" de Theodore de Bry. Vide T de Bry (1602), J. M. Cooper (1917), J. Bird (1946) e C. Markham (1911).

27. P. J. P. Whitehead \& M. Boeseman (1989).

28. Compare com F. Dainville (1964).

29. Termo utilizado para designar uma vegetação arbustiva-arbórea de porte baixo (ca. 7-8 m) restrita aos solos arenosos muito lixiviados, cuja gradação de formas provavelmente reflete a maior ou menor quantidade de material sedimentar depositado. Caracterizados por espécies como o caju (Anacardium sp.), a mangabeira (Hancornia sp.), o jatobá (Hymenea sp.) e a pitangueira (Eugenia sp.), os "tabuleiros" da Paraíba, Pernambuco e Alagoas apresentam uma fisionomia algo similar a do cerrado, tendo sido considerados pelos diferentes autores como uma formação edáfica, uma etapa de sucessão da floresta estacional ou da savana-parque e até mesmo como uma vegetação de origem antrópica. Para maiores informações, vide F. A. F. de Carvalho \& M. G. R. F. de Carvalho (1993), E. Kuhlmann (1977) e S. G. da Vinha \& D. E. V. P. Lobão (1989). 


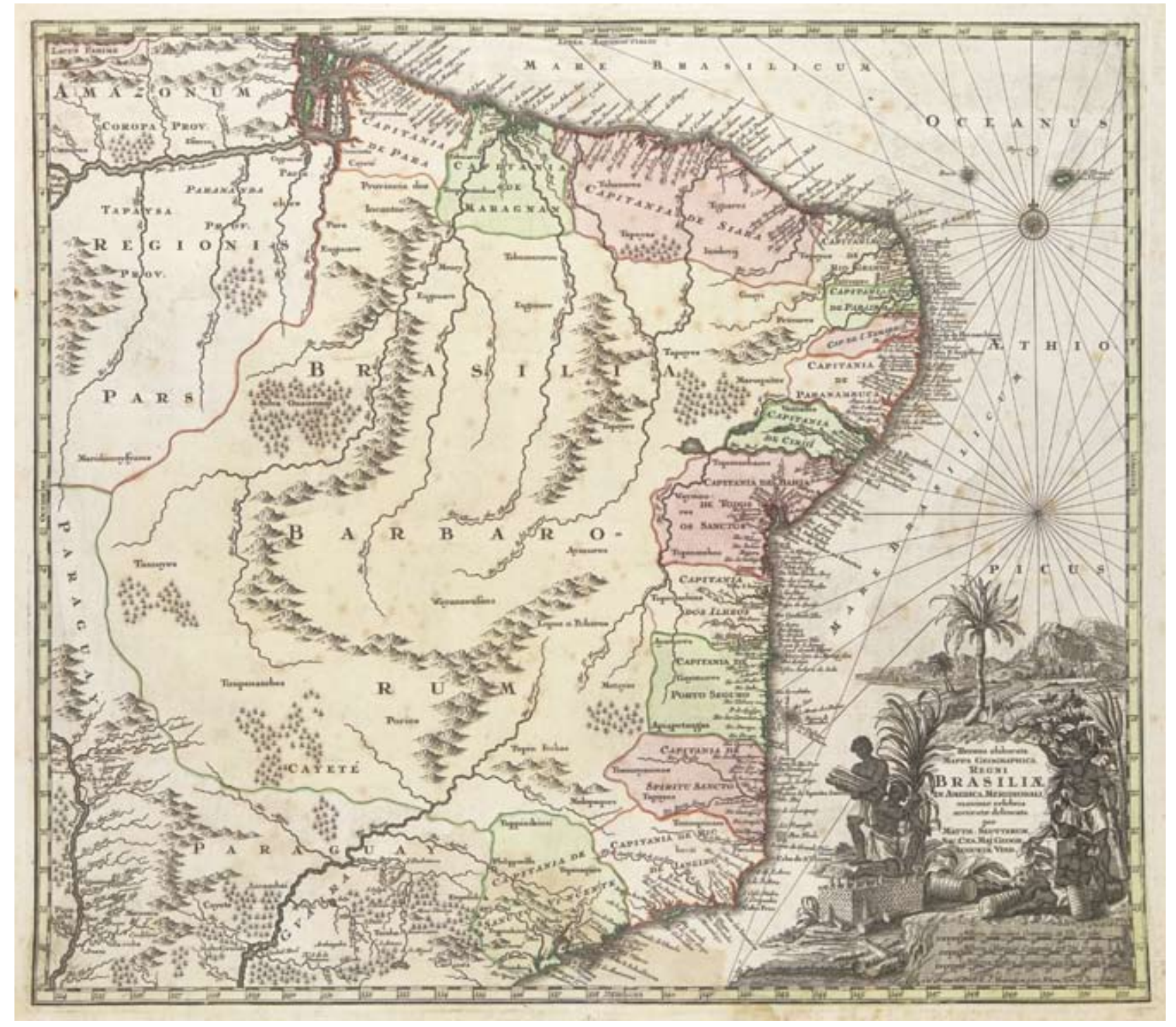

Figura 8 - O "Mappa Geographica Regni Brasiliae" de George Matthäus Seuter (ca. 1735). Os detalhes da ornamentação do cartucho mostram homens e mulheres de pele escura preparando pães-de-açúcar e rolos de fumo, tradicionais produtos agrícolas do país. Instituto de Estudos Brasileiros / USP (acervo depositado temporariamente pela Justiça Federall, São Paulo. 


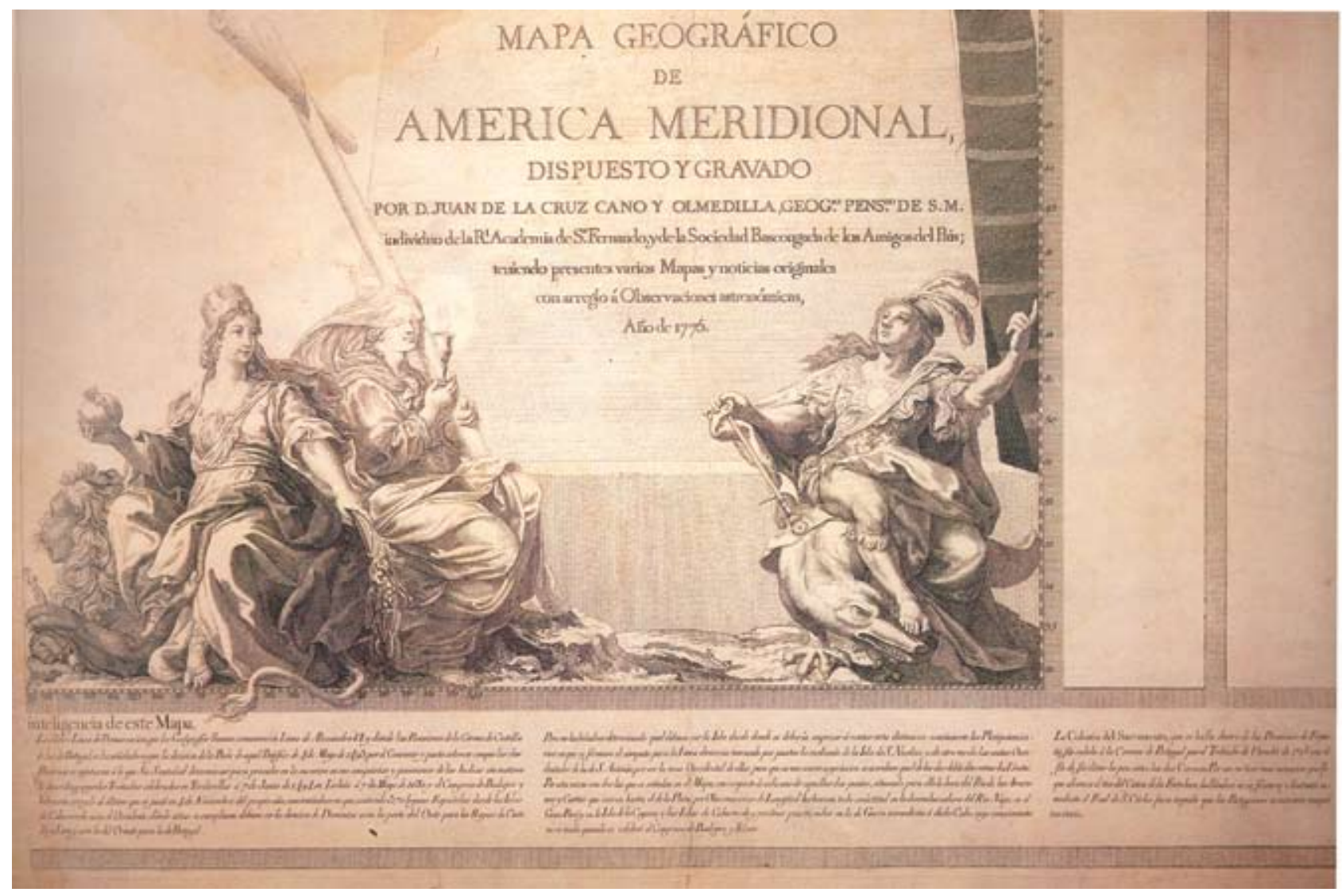

Figura 9 - A Europa e a América. Detalhe do "Mapa Geográfico da América Meridional" de Juan de la Cruz Cano y Olmedilla (1775). Mapoteca do Itamaraty, Rio de Janeiro.

penas, retrato de uma selvagem e desamparada América convocada a ingressar nas luzes da civilização, arranjo coerente com as chamadas "Alegorias dos Quatro Continentes" em voga desde o começo do século XVIII0.

Durante o século XIX, os trabalhos dos velhos cartógrafos passariam gradativamente à categoria de artigos de luxo ou suntuosos itens de coleção dignos de apreço por suas óbvias qualidades estéticas. Cada vez se faria mais difusa, portanto, a noção de que as ricas ilustrações desses originais possuíam um caráter descritivo regido por princípios não muito distintos daqueles praticados na pintura de cenas religiosas ou históricas, aqui entendidas como abstrações capazes de se materializarem graças à soma da tradição e do senso comum com o conteúdo dos clássicos, os comentários dos doutos e a autoridade de textos consagrados. Como uma imagem do mundo só pode ganhar corpo caso o mundo tenha alguma forma, restaria a esses pioneiros debruçar-se sobre as fontes disponíveis para, pouco a pouco, construir sua própria visão do universo conhecido. De certa maneira, portanto, os antigos mapas seriam verdadeiros escrínios, onde
30. H. Honour (1975) e C. Ripa (1603). 
as notícias oriundas dos "livros de viagem" dividem espaço com informações provenientes de obras da Antiguidade, grandes iconografias, compilações diversas e até mesmo do simples relato de aventureiros.

No rastro da crescente expansão europeia, o imenso espaço vazio de um orbe indevassado sofreria uma drástica redução, desdobrando-se em colônias e áreas de influência ante o vertiginoso impulso do mercantilismo dos séculos XVII e XVIII. Devido aos avanços da técnica, os cartógrafos aprenderiam rapidamente a desprezar os detalhes sobre a natureza e os habitantes locais como referência geográfica, passando a trabalhar com triangulações, meridianos e todos os sofisticados processos envolvidos no manejo e preparo de representações cada vez mais exatas das áreas trabalhadas. Em última instância, esse quadro de mudanças terminaria por decretar o fim dos soberbos mapas ilustrados, pois tanto as fascinantes maravilhas de reinos distantes quanto a inspiradora crença em um globo povoado pelas mais fabulosas criaturas estariam condenadas a desaparecer para sempre, convertendo-se em riquezas a serem exploradas, mão de obra a escravizar e terras destinadas a uma sangrenta conquista, instalando-se em definitivo no cotidiano.

\section{REFERÊNCIAS}

\section{FONTES PRIMÁRIAS}

ACOSTA, J. de. Historia natural y moral de las Indias, en que se tratan de cosas notables del cielo, y elementos, metales, plantas y animales dellas y los ritos y ceremonias, leyes y gobiernos, y guerras de los indios. Sevilla: Juan de León, 1590.

DE BRY, T. Americae tertia pars memorabil provinciae Brasiliae Historiam contin s, germanico primùm sermone scriptam à Io ne Stadio Homburgensi Hesso, nunc autem latinitate donatam à Teucrio Annaeo Priuato Colchante Po: E Med: Addita est Narratio profectionis Ioannis Lerij in eandem Provinciam, qu ille initio gallic conscripsit, postea veró Latinam fecit. Francoforti: Theodori de Bry, 1592.

DE BRY, T. Americae Nona \& postrema Pars. Francofor[ti]: Matth. Beckerum, 1602.

KIRCHER, A. Arca Noë in tres libros digesta. Amstelodami: Joannes Janssonium, 1675.

LERY, J. de Histoire d'un voyage fait en la terre du Bresil, avtrement dite Amerique. La Rochelle: Antoine Chuppin, 1578.

MANDEVILLE, J. The travels of Sir John Mandeville. London: Penguin, 1983.

[MONTALBODDO, F. da]. Paesi nouamente retrouati. Vicentia: Henrico Vicentino, 1507.

NOORT, O. van. Befchryvinghe vande Voyagie om dem geheelen Werelt Cloot, ghedaen door Olivier van Noort van Vtrech, Generael over vier Schepen, te weten: het Schip Mauritius als Admirael, dat wederom ghecomen is, Hendrick Fredrick Vice-Admirael, het Schip de Eendracht, midtfgaders de Hope, wel ghemonteert van alle Ammonitie van Oorloghe ende Victualie, op 
bebbende 248. man, om te gaen door de Strate Magellanes, te bandelen langhs de Cuften van Cica Cili ende Peru, om den gantfchen Aerden Cloot om te zeulen, ende door Moluckes wederom thuys te comen. Amftelredam: Cornelis Claeffz, 1601.

OVIEDO Y VALDEZ, G. F. De la segunda parte de la general historia delas Indias. Valladolid: Francisco Fernandez de Cordoua, 1557.

POTGIETER, B.J. Wijdtloopigh verhael van tgene de vijf Schepen (die int jaer 1598. tot Rotterdam toegheruft werden, om door de Straet Magellana haren handel te dryven) wedervaren is, tot den 7. September 1599. toe, op welcken dagh Capiteijn Sebald de Weert, met twee fchepen, door onweder vande Vlote verfteken werdt. Amsterdam: Zacharias Heijns, 1600.

[RAMUSIO, G.B.] Primo volume della Navigationi et Viaggi nel quale si contegono le Navigationi al Mondo Nuovo, alli Antichi incognito, fate da Don Christoforo Colombo Genouese, che fu il primo à scroprirlo à i Re Catbolici, detto bora le Indie occidentali, con gli acquisti fatti da lui. Venetia: Stamperia de Givnti, 1550.

[RAMUSIO, G.B.] Terzo Volvme delle Navigationi et Viaggi nel quale si contegono le Navigationi al Mondo Nuovo, alli Antichi incognito, fate da Don Cbristoforo Colombo Genouese, che fu il primo à scroprirlo à $i$ Re Catbolici, detto bora le Indie occidentali, con gli acquisti fatti da lui. Venetia: Stamperia de Givnti, 1556.

RIPA, C. Iconologia. Roma: Lepido Faeij, 1603.

SOLINUS, C. J. The excellent and pleasant worke of Iulius Solinus Polybistor. London: Thomas Hacket, 1587.

SOUSA, P. L. de. O diário de navegação de Pero Lopes de Sousa 1500-1532. Rio de Janeiro: Comissão Brasileira dos Centenários Portugueses, 1940.

STADEN, H. Warhaftige Historia vnd beschreibung eyner Landtschafft der Wilden, Nacketen, Grimmigen Menschfresser Leuthen, in der Newewelt America gelegen, vor vnd nach Christi geburt im Land zü Hessen vnbekant, biss vff disse ij. nechst vergangene jar, Da sie Hans Staden von Homberg auss Hessen durch den truck an tag gibt. Marpurg: Andres Kolben, 1557.

THEVET, A. Les singvlaritez de la France Antarctique, avtrement nommé Amerique: É de plusieurs terres $\mathcal{E}$ isles decounertes de nostre temps. S. Claude: Maurice de la Porte, 1557.

\section{BIBLIOGRAFIA}

BROWN, L. A. The Story of Maps. New York: Bonanza, 1949.

BROWNE, J. The Secular Ark: studies in the history of biogeography. New Haven: Yale University Press, 1983.

CAMPBELL, M. B. The Witness and the Other World: Exotic European Travel Writing, 1400-1600. Ithaca: Cornell University Press, 1988. 
CARVAlho, F. A. F. de; CARVAlho, M. G. R. F. de. A devastação dos cerrados (tabuleiros) do litoral do Estado da Paraíba. Revista Nordestina de Biologia, João Pessoa, v. 8, n. 2, p. 107-112, 1993.

COOPER, J. M. Analytical and Critical Bibliography of the Tribes of Tierra del Fuego and Adjacent Territory. Bureau of American Ethnology Bulletin, Washington, v. 63, p. 1-233, 1917.

CORTESÃO, J. A expedição de Pedro Alvares Cabral e o descobrimento do Brazil. Lisboa: Aillaud \& Bertrand, 1922.

DAINVILLE, F. de. Le langage des géographes: termes, signes, couleurs des cartes anciennes 1500-1800. Paris: A. et J. Picard, 1964.

DREYER-EIMBCKE, O. Die Entdeckung der Erde: Geschichte und Geschichten des kartographischen Abenteures. Frankfurt am Main: Umschau, 1988.

FAVIER, J. Les grandes découvertes. Paris: Arthème Fayard, 1991.

GEORGE, W. Animals on maps. London: Secker and Warburg, 1969.

GERBI, A. La naturaleza de las Indias nuevas. México DF: Fondo de Cultura Económica, 1978.

GERBI, A. La disputa del Nuevo Mondo: historia de una polémica 1750-1900. México DF: Fondo de Cultura Económica, 1993.

GLACKEN, C. J. Traces on the Rbodian Sbore: Nature and Culture in Western Thought from Ancient Times to the End of the Eighteenth Century. Berkeley: University of California Press, 1976.

GRAY, G. R. List of the Specimens of Birds in the Collection of the British Museum. Part III, Section II: Psittacidae. London: Trustees of the British Museum, 1859.

GREENLEE, W. B. The voyage of Pedro Álvares Cabral to Brazil and India. London: Hakluyt Society, 1938.

GUEDES, M. J. O descobrimento do Brasil. Lisboa: Vega, 1997.

JACOB, C. L' empire des cartes. Paris: Albin Michel, 1992.

HONOUR, H. The New Golden Land: European Images of America from the Discoveries to the Present Time. New York: Pantheon, 1975.

KAPPLER, C. C. Monstres, démons et merveilles à la fin du Moyen Age. Paris: Payot \& Rivages, 1999.

KRETSCHMER, K. Historia de la geografía. Barcelona: Labor, 1942.

KUHLMANN, E. Vegetação. In: GEOGRAFIA DO BRASIL: Região Nordeste. Rio de Janeiro: Instituto Brasileiro de Geografia e Estatística, 1977. p. 85-110.

LESTRINGANT, F. L'automne des cannibales ou les outils de la Conquête. In: DUCHET, M. (Org.), L'Amérique de Théodore de Bry: une collection de voyages protestante du XVIe siècle, quatre 
études d' iconographie. Paris: Editions du Centre National de la Recherche Scientifique, 1987. p. 69-104.

MARKHAM, C. Early Spanish Voyages to the Strait of Magellan. London: Hakluyt Society, 1911.

MARTÍN-MERÁS, L. Cartografía marítima bispana: la imagen de América. Madrid: Lunwerg Editores, [1993].

MOLLAT, M. Les explorateurs du XIIIe au XVIe siècle: premiers regards sur des mondes nouveaux. Paris: Jean-Claude Lattès, 1984.

MORELAND, C.; BANNISTER, D. Antique maps. London: Phaidon, 1989.

PAPAVERO, N.; TEIXEIRA, D. M.; LLORENTE-BOUSQUETS, J. História da Zoogeografia no período pré-evolutivo. São Paulo: Plêiade, 1997.

POLLARD, J. Birds in Greek Life and Myth. London: Thames and Hudson, 1977.

ROUX, J. P. Les explorateurs au Moyen Age. Paris: Arthème Fayard, 1985.

SICK, H. Brasilianischer Ara 1502/03 in Europa gemalt. Journal für Ornithologie, Berlim, v. 125, n. 4 , p. $479-481,1984$.

SOBEL, D. Longitude. New York: Walker, 1995.

SOLINUS, C. J. The excellent and pleasant worke of Iulius Solinus Polybistor. London: Thomas Hacket, 1587.

SOUZA, B. J. de. O pau-brasil na bistória nacional. São Paulo: Companhia Editora Nacional, 1939.

SOUZA, T. O. M. de. O descobrimento do Brasil de acordo com a documentação bistórica e cartográfica. São Paulo: Nacional, 1946.

STEWARD, J. H. (Org.). Handbook of South American Indians, 1: The Marginal Tribes. Bureau of American Ethnology Bulletin, Washington, v. 143, p. 1-624, 1946.

TEIXEIRA, D. M.; NACINOVIC, J. B. O guano de aves marinhas no Brasil. Publicações Avulsas do Museu Nacional, Rio de Janeiro, n. 95, p. 1-66, 2002.

TEIXEIRA, D. M.; PAPAVERO, N. Os animais do descobrimento: a fauna brasileira mencionada nos documentos relativos à viagem de Pedro Álvares Cabral (1500-1501). Publicações Avulsas do Museu Nacional, Rio de Janeiro, n. 111, p. 1-133, 2006.

TOOLEY, R. V. Maps and map-makers. London: B.T. Batsford, 1952.

TOYNBEE, J. M. C. Animals in Roman Life and Art. London: Thames and Hudson, 1973.

VINHA, S. G. da; LOBÃO, D. E. V. P. Estação Ecológica do Pau-Brasil, Porto Seguro, Babia. Ilhéus: Centro de Pesquisas do Cacau, 1989.

Annals of Museu Paulista. v. 17. n.1. Jan. - June 2009. 
WHITEHEAD, P. J. P.; BOESEMAN, M. A Portrait of Dutch 17th century Brazil: Animals, Plants and People by the Artists of Johan Maurits of Nassau. Amsterdam: North-Holland, 1989.

ZANDVLIET, K. Mapping for Money: Maps, Plans and Topographic Paintings and Their Role in Dutch Overseas Expansion during the 16th and 17th Centuries. Amsterdam: Batavia Lion International, 2002.

ZIEBELL, Z. Terra de canibais. Porto Alegre: Editora da Universidade Federal do Rio Grande do Sul, 2002.

ZUCKERMAN, S. The Ape in Myth \& Art. London: Verdegris, 1998.

Artigo apresentado em 8/2008. Aprovado em 12/2008. 